\title{
OPEN Effect of straw biochar amendment on tobacco growth, soil properties, and rhizosphere bacterial communities
}

\author{
Jiayu Zheng ${ }^{1,5}$, Jixu Zhang ${ }^{1,3,5}$, Lin Gao ${ }^{1}$, Rui Wang ${ }^{2}$, Jiaming Gao ${ }^{2}$, Yanchen Dai ${ }^{1}$, Wei $\mathrm{Li}^{4}$, \\ Guoming Shen ${ }^{1}$, Fanyu Kong ${ }^{1} \&$ Jiguang Zhang ${ }^{1 凶}$
}

Biochar is an effective soil conditioner. However, we have limited understanding of biochar effects on the tobacco growth and bacterial communities in rhizosphere. The aim of this study was to investigate the effects of different straw biochar amendment $(0,2,10$, and $50 \mathrm{~g} / \mathrm{kg}$ dry soil) on tobacco growth, soil properties, and bacterial communities in rhizosphere by pot trials. Most of tobacco agronomic traits increased when the application rate varied from 0 to $10 \mathrm{~g} / \mathrm{kg}$, but were inhibited by $50 \mathrm{~g} / \mathrm{kg}$ of biochar application. Soil $\mathrm{pH}, \mathrm{SOC}$, available nutrients and soil urease, invertase, and acid phosphatase activities were all increased with the biochar application, whereas catalase activity decreased or remained unchanged. The OTUs and bacterial community diversity indices differed with the biochar application doses in rhizosphere and non-rhizosphere soils. And significant differences in bacterial communities were found between the rhizosphere and non-rhizosphere soils despite the biochar addition. Firmicutes, Proteobacteria, Acidobacteria, Bacteroidetes, and Actinobacteria were the dominant phyla in all soil samples, but they had different abundances in different treatment influenced by the rhizosphere and biochar effect. The high dose of biochar $(50 \mathrm{~g} / \mathrm{kg})$ decreased the similarity of soil bacterial community structure in rhizosphere compared with those in non-rhizosphere soil. These results provide a better understanding of the microecological benefits of straw biochar in tobacco ecosystem.

Biochar is a carbon-rich by-product of thermal degradation of organic materials under anaerobic environment (i.e. pyrolysis), and it can be distinguished from charcoal owing to its soil amendment properties ${ }^{1}$. Biochar contains large amounts of carbon and macro- or micro-nutrients, which depends on the feedstock and pyrolysis temperature ${ }^{2,3}$. It can be produced from a wide range of biomass sources, such as woody materials, agricultural waste, animal manure, and other waste products ${ }^{4-6}$. Biochar is gaining recognition from scientists and policy makers for its potential role in carbon sequestration, reduction of greenhouse gas emissions, renewable energy production, waste mitigation, and soil amendment ${ }^{1}$.

Previous studies have reported biochar as a soil conditioner used for enhancing soil fertility and crop productivity in different soils, crops, and agroecosystems $\mathrm{s}^{7-9}$. The observed effects of biochar on soil fertility are $\mathrm{pH}$ adjustment in acid soils and improvement in nutrient retention through cation adsorption ${ }^{10}$. The amendment of agricultural soils with different types of biochar had variable effects on soil properties depending on the soil type, biochar feedstock, and amendment rate ${ }^{11}$. Meanwhile, some studies showed that high biochar addition rate had negative effects on soil quality and crop quantity parameters, such as short-term reduction in soil mineral $\mathrm{N}$ availability ${ }^{4,12}$, inhibition of soil microbial biomass and activity ${ }^{13}$, and inhibition of crop yield ${ }^{14}$. Furthermore, biochar addition had different effects on plant disease resistance according to biochar dose and biochar type $\mathrm{e}^{15,16}$.

Enzymatic assays are a valuable tool for understanding the soil metabolic activity that underpins processes, such as mineralization and humification of soil organic matter. Soil enzymes are catalysts of organic matter decomposition, and they are involved in biogeochemical nutrient cycling ${ }^{16}$, including carbon (C), nitrogen

\footnotetext{
${ }^{1}$ Tobacco Research Institute of Chinese Academy of Agricultural Sciences, Qingdao 266101, People's Republic of China. ${ }^{2}$ Tobacco Company of Hubei Province, Wuhan 430030, People's Republic of China. ${ }^{3}$ Kunming Tobacco Company, Kunming 651500, People's Republic of China. ${ }^{4}$ China Tobacco Jiangsu Industrial Co., Ltd., Nanjing 210019, People's Republic of China. ${ }^{5}$ These authors contributed equally: Jiayu Zheng and Jixu Zhang. ${ }^{\varpi}$ email: zhangjiguang@caas.cn
} 
$(\mathrm{N})$, phosphorous (P), and sulfur (S) cycling. Recently, some studies have reported that biochar addition to soil increased the activity of soil enzymes related to $\mathrm{N}$ and $\mathrm{P}$ cycling and reduced the activity of soil enzymes involved in $\mathrm{C}$ cycling ${ }^{17,18}$. Conversely, other studies have obtained inconsistent results ${ }^{16}$, which suggested that biochar has variable effects on different soils, enzymes, and assay types.

Soil physicochemical properties can be affected by biochar application, which changes the habitat for microbial colonization, thereby affecting soil microbial activity and microbial community structure ${ }^{19,20}$. Changes in mic robial communities can be associated with changes in soil nutrients, $\mathrm{pH}$, and physical properties after biochar addition ${ }^{21,22}$. Some studies found that biochar addition could affect soil bacterial and fungal community structure ${ }^{23,24}$. Crop rhizosphere is known to be a hotspot for microbial diversity as well as to contain different microbial communities than bulk soil ${ }^{25}$. Biochar may alter the soil microbial community structure, which can consequently change the physical interactions between plant roots and microorganisms ${ }^{26}$. However, despite its critical importance for nutrient acquisition and soil-borne disease control, the effects of biochar on rhizosphere microbial communities are not well understood and need to be further studied ${ }^{27}$.

Flue-cured tobacco (Nicotiana tabacum L.), one of the most important industrial crops, is extensively planted in the south-central region of China. The effect of biochar on soil physicochemical properties, plant growth, and the rhizosphere microbiome of different crops has been studied frequently ${ }^{7,12,15,19,22}$. However, most studies were conducted in bulk or in greenhouses and focused on rhizosphere soil only. Straw biochar, as a soil amendment, began to be applied into tobacco field in recent years, and the related research is still at an early stage. Hence, the aim of this study was to evaluate the effect of biochar addition on tobacco growth, soil nutrients, enzymes, and the rhizosphere bacterial community structure using a pot experiment, and to determine whether the changes in the bacterial community in the rhizosphere and non-rhizosphere soil are consistent after biochar application. We hypothesized that the biochar would have a different effect on rhizosphere bacteria compared with the nonrhizosphere soil, which directly drives the process of nutrient transformation and hence the growth of tobacco.

\section{Materials and methods}

Site description and experiment description. The pot experiment was conducted in 2017 at the Wangchengpo Modern Tobacco Agricultural Science and Technology Park in Enshi City, Hubei Province, China. The test soil for the experiment was collected from mature tobacco fields in the village of Mao Bacao, Baiguo Town, Hubei Province. The main characteristics of the soil prior to experimentation were as follows: $\mathrm{pH}$ 6.9; soil organic carbon, $19.29 \mathrm{~g} / \mathrm{kg}$; alkali-hydrolysable $\mathrm{N}, 86.25 \mathrm{mg} / \mathrm{kg}$; available phosphorus (Olsen-P), $76.15 \mathrm{mg} / \mathrm{kg}$; and extractable K, $292.82 \mathrm{mg} / \mathrm{kg}$. The tested soil was classified as Haplic Luvisol (UNESCO soil classification system) and characterized as a silty loam.

The following five treatments were used in the pot experiment: CK1 (without fertilizer and biochar addition), CK2 (with fertilizer addition and without biochar addition), T1 [fertilizer $+0.2 \%$ biochar ( $2 \mathrm{~g} / \mathrm{kg}$ soil dry weight) addition], T2 treatment [fertilizer $+1.0 \%$ biochar $(10 \mathrm{~g} / \mathrm{kg}$ soil dry weight $)$ addition], and T3 treatment [fertilizer $+5.0 \%$ biochar $(50 \mathrm{~g} / \mathrm{kg}$ soil dry weight $)$ addition $]$. The soil was air-dried, passed through a sieve with 2-mm mesh size, and mixed with chemical fertilizers ( $4 \mathrm{~g} \mathrm{~N}$ per pot and $\mathrm{N}: \mathrm{P}_{2} \mathrm{O}_{5}: \mathrm{K}_{2} \mathrm{O}=1: 1.5: 3$, in line with the amount of chemical fertilizer applied in the local tobacco planting area). The amount of chemical fertilizer applied in all treatments (except CK1) was also equivalent to that in the local tobacco field. Biochar was crushed and then passed through a sieve with $2 \mathrm{~mm}$ mesh size and mixed with the soil and chemical fertilizers in the pots. Each plastic pot was filled with $15 \mathrm{~kg}$ sieved soil, and watered until $60 \%$ water holding capacity (WHC) during the experimental period. The treatments were conducted in five replicates each. The tested flue-cured tobacco variety was "Yunyan 87", and the plants were transplanted to one plant/pot on May 10. Biochar was provided by the Institute of Soil Science, Chinese Academy of Sciences. The biochar was produced from rice straw. The conversion of the rice straw to biochar was accomplished under slow pyrolysis, at a heating rate of $10{ }^{\circ} \mathrm{C} / \mathrm{min}$ to a highest temperature of $500{ }^{\circ} \mathrm{C}$, with a $4 \mathrm{~h}$ residence time. The main characteristics of rice straw biochar were as follows: $\mathrm{pH} 9.2$; total carbon, $630 \mathrm{~g} / \mathrm{kg}$; total nitrogen, $13.5 \mathrm{~g} / \mathrm{kg}$; ash content, $140 \mathrm{~g} / \mathrm{kg}$; total phosphorus, $4.50 \mathrm{~g} /$ $\mathrm{kg}$; total potassium, $21.5 \mathrm{~g} / \mathrm{kg}$; total cadmium, $0.69 \mathrm{mg} / \mathrm{kg}$; total arsenic, $0.78 \mathrm{mg} / \mathrm{kg}$; total lead, $5.60 \mathrm{mg} / \mathrm{kg}$; total chromium, $9.09 \mathrm{mg} / \mathrm{kg}$, and total nickel, $5.71 \mathrm{mg} / \mathrm{kg}$.

The soil that was strongly adhered to the roots and within the area influenced by the roots was considered as rhizosphere soil (R-soil) ${ }^{28}$. R-soil samples were collected from mature tobacco plants on September 5, 2017 by the root-shaking method ${ }^{29}$. Meanwhile, the non-rhizosphere soil (N-soil) samples were collected from five points in each pot using a soil corer, mixed, and homogenized to acquire approximately $0.5 \mathrm{~kg}$ of the final samples. Soil samples (200 g) were air-dried and further sieved through a $2 \mathrm{~mm}$ mesh size for chemical and enzyme activity analysis. The remaining R-soil (RCK1, RCK2, RT1, RT2, and RT3) and N-soil samples (NCK1, NCK2, $\mathrm{NT} 1, \mathrm{NT} 2$, and NT3) were collected and stored at $-80^{\circ} \mathrm{C}$ for further analyses of the soil microbial community.

Tobacco agronomic traits analysis. Five pots per treatment were used to record the main agronomic trait indices of mature tobacco (September 5, 2017). Tobacco height, stem girth, and number of productive leaves were measured with a tape. Meanwhile, three representative tobacco plants were selected, and their entire root systems were pulled out and rinsed thoroughly with water. The roots, stems, and leaves of tobacco plants were taken as samples. These samples were heated at $105^{\circ} \mathrm{C}$ for $30 \mathrm{~min}$ and then dried at $65{ }^{\circ} \mathrm{C}$ for $72 \mathrm{~h}$ to a constant weight followed by the measurement of the biomass of three samples. All methods were performed in accordance with the relevant guidelines and regulations ${ }^{30}$.

Soil chemical properties. The soil $\mathrm{pH}$ was measured electrometrically in distilled water solution at a 1:2.5 (w/v) ratio. Soil organic carbon was determined through the potassium dichromate method. Available N (alkalihydrolyzable $\mathrm{N}$ ) was determined by the alkali solution method and available P was determined by using Olsen's 
method $^{31}$, which is a colorimetric estimation using ammonium molybdate after extraction of phosphate with sodium bicarbonate. Available K (extractable K) was determined by a flame photometer using ammonium acetate. All the above methods have been described in detail in Sparks et al. (1996) ${ }^{32}$.

Soil enzyme analysis. Enzymatic activities of sucrase, urease, and acid phosphatase in the soil were measured using the principles of colorimetry. Catalase activity was determined by volumetric titration. Sucrase activity was determined by 3,5-dinitrosalicylic acid colorimetry using sucrose as the substrate, and it was expressed as $\mathrm{mg}$ glucose/g dry soil $24 \mathrm{~h}^{-133}$. Soil urease activity was measured using indophenol colorimetry with urea as the substrate. Ammonium ions were released over $1 \mathrm{~h}$ and assayed calorimetrically at $578 \mathrm{~nm}$. Soil urease activity was expressed as $\mathrm{mg} \mathrm{NH} \mathrm{NH}^{4+}-\mathrm{N} / \mathrm{kg}$ dry soil/ $\mathrm{h}^{34}$. Soil acid phosphatase activity was determined by phenyl phosphate colorimetry according to Guan $(1986)^{35}$, and catalase activity was determined according to Xu and Zheng $(1986)^{36}$. Acid phosphatase activity was expressed as $\mathrm{mg}$ pnitrophenol/g dry soil/d, and catalase activity was expressed as $\mathrm{ml}$ of $0.02 \mathrm{~N} \mathrm{KMnO}_{4} / \mathrm{g}$ dry soil/min. The above estimations of enzymatic activities were performed in triplicates and their mean values were reported.

Soil DNA extraction and polymerase chain reaction (PCR) sequencing. The total genome DNA from soil samples was extracted by following the instructions of the Power Soil DNA extraction kit (MOBIO, USA). The integrity of the DNA was determined by $1 \%$ agarose gel electrophoresis, while the purity and concentration of the DNA were assessed using Nanodrop microvolume spectrophotometer (Thermo Fisher Scientific, Waltham, MA, USA).

The universal 16S/18S rRNA genes were amplified using barcoded primers (16S V4: 515F-806R, 18S V4: 528F-706R, ITS1: ITS1F- ITS2). All PCR reactions were carried out in $30 \mu \mathrm{L}$ capacity reactors with $15 \mu \mathrm{L}$ of Phusion High-Fidelity PCR Master Mix (New England Biolabs); $0.2 \mu \mathrm{M}$ of forward and reverse primers; and about $10 \mathrm{ng}$ template DNA. Thermal cycling consisted of initial denaturation at $98^{\circ} \mathrm{C}$ for $1 \mathrm{~min}$, followed by 30 cycles of denaturation at $98^{\circ} \mathrm{C}$ for $10 \mathrm{~s}$, annealing at $50^{\circ} \mathrm{C}$ for $30 \mathrm{~s}$, elongation at $72{ }^{\circ} \mathrm{C}$ for $60 \mathrm{~s}$, and finally subjection to $72{ }^{\circ} \mathrm{C}$ for $5 \mathrm{~min}$. The same volume of $1 \mathrm{X}$ loading buffer (containing SYB green) with PCR products were mixed and electrophoresis was initiated on 2\% agarose gel for detection. Samples with bright strip between 400 and 450 base pairs (bp) were chosen for further experimentation. PCR products were mixed in ratios of equal density. Later, this mixture was purified with a Gene JET Gel Extraction Kit (Thermo Scientific). Sequencing libraries were generated using NEB Next Ultra DNA Library Prep Kit for Illumina (NEB, USA) following manufacturer's recommendations, and index codes were added. The library quality was assessed on the Qubit 2.0 Fluorometer (Thermo Scientific) and Agilent Bioanalyzer 2100 system. Finally, the library was sequenced on an Illumina MiSeq platform at Majorbio Bio-Pharm Technology Co., Ltd. (Shanghai, China) and $250 \mathrm{bp} / 300 \mathrm{bp}$ paired-end reads were generated. Raw reads were deposited in the NCBI Sequence Read Archive (SRA) database. Data were also analysed by Majorbio Bio-Pharm Technology Co., Ltd. (Shanghai, China).

Pyrosequencing data processing. Sequences were processed using the quantitative insights in microbial ecology (QIIME) pipeline v.1.3.037. After sequence splitting by barcode, pre-processing filtration was done using default settings along with $600 \mathrm{bp}$ maximum sequence length to account for length amplification. The remaining sequences (33.6\%) were clustered using uclust ${ }^{38}$ into OTUs (operational taxonomic units) with a 0.03 dissimilarity index ( $97 \%$ sequence similarity). Paired-end reads from the original DNA fragments were merged using $\mathrm{FLASH}^{39}$, which has been designed to merge paired-end reads when some of the reads overlap with the read generated from the opposite end of the same DNA fragment. Paired-end reads were assigned to each sample according to the unique barcodes. Sequences analysis was performed by UPARSE software package using the UPARSE-OTU and UPARSE-OUT ref algorithms. In-house Perl scripts were used to analyze alpha (within samples) and beta (among samples) diversity. Sequences with $\geq 97 \%$ similarity were assigned to the same OTUs. We picked a representative sequence for each OTU and used the ribosomal database project (RDP) classifier to annotate taxonomic information for each representative sequence. To compute alpha diversity, we refined the OTU table and calculated the following metrics: Chao and Abundance-based Coverage Estimator (ACE) indices for species abundance, observed species index for quantitative estimation of unique OTUs in each sample, and the Shannon and Simpson indices. Graphical representation of the relative abundance of bacterial diversity from the phylum to the gene level can be visualised using a Krona chart. We used the unweighted pair group method with Arithmetic mean (UPGMA) clustering ${ }^{37}$. UPGMA Clustering is a type of hierarchical clustering method using average linkage and can be used to interpret the distance matrix.

Statistical analysis. In the present study, Shannon's index and Simpson's index (D) were used to estimate the diversity of microbial community. A high value of Shannon's index indicates high diversity; while a low value of D, indicates high diversity. Chaol and ACE were used to estimate the richness of microbial community, where high values of the two indices indicate high community richness. Phylogenetic distance and the Shannon index were computed in QIIME. Overall, bacterial communities' structural changes were evaluated by principal coordination analysis (PCoA) with the genescloud tools (https://www.genescloud.cn). Permutational Multivariate Analysis of Variance (PERMANOVA) were used to perform the beta-diversity analysis. The differences in soil properties, soil enzyme activities and alpha diversity of bacterial communities between treatments were tested by One-way Analysis of Variance (ANOVA). The data obtained in the experiment were analysed using SPSS 16.0. (SPSS Inc., Chicago, IL, USA). Multiple comparisons were used to determine the significant difference among the treatments at $p<0.05$. 


\begin{tabular}{|l|l|l|l|l|l|l|}
\hline Treatments & Plant height $(\mathbf{c m})$ & Stem girth $(\mathbf{c m})$ & $\begin{array}{l}\text { Productive leaves } \\
\text { number }\end{array}$ & Root biomass $(\mathbf{g})$ & Stem biomass $(\mathbf{g})$ & $\begin{array}{l}\text { Leaves biomass } \\
(\mathbf{g})\end{array}$ \\
\hline CK1 & $86.21 \mathrm{c}$ & $5.11 \mathrm{a}$ & $18.31 \mathrm{~b}$ & $8.01 \mathrm{~b}$ & $16.21 \mathrm{~d}$ & $32.21 \mathrm{~d}$ \\
\hline CK2 & $112.00 \mathrm{ab}$ & $5.37 \mathrm{a}$ & $21.33 \mathrm{a}$ & $9.17 \mathrm{c}$ & $24.53 \mathrm{~b}$ & $45.46 \mathrm{ab}$ \\
\hline T1 & $115.67 \mathrm{ab}$ & $5.33 \mathrm{a}$ & $21.67 \mathrm{a}$ & $9.70 \mathrm{bc}$ & $27.89 \mathrm{a}$ & $48.47 \mathrm{a}$ \\
\hline T2 & $127.33 \mathrm{a}$ & $5.83 \mathrm{a}$ & $21.00 \mathrm{ab}$ & $10.83 \mathrm{~b}$ & $23.21 \mathrm{~b}$ & $48.67 \mathrm{a}$ \\
\hline T3 & $103.00 \mathrm{~b}$ & $5.17 \mathrm{a}$ & $19.33 \mathrm{~b}$ & $11.99 \mathrm{a}$ & $19.64 \mathrm{c}$ & $40.21 \mathrm{c}$ \\
\hline
\end{tabular}

Table 1. Effect of straw biochar application on the agronomic traits and biomass of tobacco at mature stage. Different letters in each column indicate significant differences $(p<0.05)$ among the treatments for each parameter.

\begin{tabular}{|l|l|l|l|l|l|}
\hline Treatments & $\mathbf{p H}$ & Organic carbon $(\mathbf{g} / \mathbf{k g})$ & Available nitrogen $(\mathbf{m g} / \mathbf{k g})$ & $\begin{array}{l}\text { Available phosphorus } \\
(\mathbf{m g} / \mathbf{k g})\end{array}$ & $\begin{array}{l}\text { Available potassium }(\mathbf{m g} / \\
\mathbf{k g})\end{array}$ \\
\hline CK1 & $6.35 \mathrm{c}$ & $11.24 \mathrm{c}$ & $79.82 \mathrm{~d}$ & $58.76 \mathrm{~d}$ & $568.21 \mathrm{e}$ \\
\hline CK2 & $6.38 \mathrm{c}$ & $11.39 \mathrm{c}$ & $92.18 \mathrm{c}$ & $81.97 \mathrm{c}$ & $695.49 \mathrm{~d}$ \\
\hline T1 & $6.56 \mathrm{c}$ & $12.32 \mathrm{bc}$ & $105.48 \mathrm{c}$ & $87.40 \mathrm{bc}$ & $994.16 \mathrm{c}$ \\
\hline T2 & $7.12 \mathrm{~b}$ & $13.00 \mathrm{~b}$ & $124.09 \mathrm{~b}$ & $92.26 \mathrm{~b}$ & $1373.12 \mathrm{~b}$ \\
\hline T3 & $7.72 \mathrm{a}$ & $43.92 \mathrm{a}$ & $140.05 \mathrm{a}$ & $118.88 \mathrm{a}$ & $2352.77 \mathrm{a}$ \\
\hline
\end{tabular}

Table 2. Effect of straw biochar application on soil chemical properties. Different letters in each column indicate significant differences $(p<0.05)$ among the treatments for each parameter.

\section{Results}

Effect of biochar on tobacco agronomic traits. The significant difference test results for effect on tobacco growth performance after biochar application is shown in Table 1. Overall, the growth performance of tobacco was the lowest in CK1 treatment. The highest growth performance of tobacco was observed in T2, and which was significantly different from T3, which showed the lowest growth performance among all biochar addition treatments. There were no significant differences between the growth performance of tobacco in T2, T1, and CK2. Additionally, there were no significant differences in the stem girth of tobacco with and without biochar application $(p>0.05)$.

The root biomass of tobacco decreased in the order T3 $>$ T2 $>$ T1 $>$ CK2 $>$ CK1; there were significant differences between the root biomasses in T3, T2, and CK2. The stem biomass decreased in the order $\mathrm{T} 1>\mathrm{CK} 2>\mathrm{T} 2>\mathrm{T} 3>\mathrm{CK} 1$, and a significant difference was observed between the stem biomass in T1 and CK2 as well as between T3 and CK2. The leaf biomass decreased in the order T2 $>$ T1 $>$ CK2 $>$ T3 $>$ CK1, and a significant difference was seen between the leaf biomass in T3, T1, and T2. Based on these results, we can conclude that an appropriate dose of biochar can promote tobacco growth, but higher doses of biochar $(50 \mathrm{~g} / \mathrm{kg}) \mathrm{can}$ inhibit tobacco growth.

Effects of biochar on soil chemical properties. The changes in soil chemical properties in response to biochar application are shown in Table 2. Overall, soil $\mathrm{pH}$, organic carbon, and available nitrogen, phosphorus, and potassium increased with the increase in biochar doses. The highest $\mathrm{pH}$ (7.72) was observed in T3, followed by T2, and they were significantly higher than that in other treatments. Soil organic carbon in T3 was significantly $(p<0.05)$ higher than in the other treatments. Available nitrogen and available potassium in soil showed similar trends, and the highest values were both in T3, which were significantly higher than those in other treatments. Available phosphorus in T1 was not significantly different from CK2 and T2. Low dose of biochar addition $(2 \mathrm{~g} / \mathrm{kg})$ did not significantly improve the soil chemical properties, except for improvement in the available potassium content. However, higher doses of biochar addition $(10 \mathrm{~g} / \mathrm{kg}$ and $50 \mathrm{~g} / \mathrm{kg})$ significantly improved the soil chemical properties.

Effects of biochar on soil enzyme activities. The effects of enzyme activities to biochar application are shown in Table 3. All soil enzyme activities except for catalase activity showed low effects in CK1. Soil urease, invertase, and acid phosphatase activities increased to different extents with the increase in biochar application. Soil urease activity for different treatments was in the order T3 $>$ T1 $>$ T2 $>$ CK2 $>$ CK1, and it increased by $13.16 \%, 2.63 \%$, and $121.05 \%$ in T1, T2, and T3, respectively, compared to CK2. In addition, urease activity was significantly higher in $\mathrm{T} 3$ than other treatments. Soil invertase activity was in the order T3 $>\mathrm{T} 2>\mathrm{T} 1>\mathrm{CK} 2>\mathrm{CK} 1$, and it increased by $70.59 \%, 82.35 \%$, and $376.47 \%$, in T1, T2, and T3, respectively, compared to CK2. And the invertase activity was significantly higher in T3 than T1, T2 and CK2. Acid phosphatase activity decreased in the order of $\mathrm{T} 1>\mathrm{T} 2>\mathrm{T} 3>\mathrm{CK} 2>\mathrm{CK} 1$, and it increased by $40.82 \%, 34.69 \%$, and $6.12 \%$ in $\mathrm{T} 1$, $\mathrm{T} 2$, and $\mathrm{T} 3$, respectively, compared to CK2. There were no significant differences among the three biochar addition treatments. However, catalase activity demonstrated a different trend compared to other enzymes, and it decreased in the 


\begin{tabular}{|c|c|c|c|c|}
\hline Treatments & Urease activities $\left(\mathrm{NH}_{3}-\mathrm{N} \mathrm{mg} \mathrm{g}^{-1} \mathrm{~d}^{-1}\right)$ & Invertase activities (Glu $\mathrm{mg} \mathrm{g}^{-1} \mathrm{~d}^{-1}$ ) & $\begin{array}{l}\text { Acid phosphatase activities (Phenol } \\
\mathrm{mg} \mathrm{g}^{-1} \mathbf{d}^{-1} \text { ) }\end{array}$ & $\begin{array}{l}\text { Catalase activities }\left(0.02 \mathrm{~mol} \mathrm{~L}^{-1}\right. \\
\left.\mathrm{KMnO}_{4} \mathrm{ml} \mathrm{g}^{-1} \mathrm{~min}^{-1}\right)\end{array}$ \\
\hline CK1 & $0.37 \mathrm{~b}$ & $0.16 \mathrm{c}$ & $0.48 \mathrm{~b}$ & $0.15 \mathrm{a}$ \\
\hline CK2 & $0.38 \mathrm{~b}$ & $0.17 \mathrm{c}$ & $0.49 \mathrm{~b}$ & $0.16 \mathrm{a}$ \\
\hline $\mathrm{T} 1$ & $0.43 \mathrm{~b}$ & $0.29 \mathrm{~b}$ & $0.69 \mathrm{a}$ & $0.08 \mathrm{~b}$ \\
\hline $\mathrm{T} 2$ & $0.39 \mathrm{~b}$ & $0.31 \mathrm{~b}$ & $0.66 \mathrm{a}$ & $0.07 \mathrm{~b}$ \\
\hline T3 & $0.84 \mathrm{a}$ & $0.81 \mathrm{a}$ & $0.52 \mathrm{ab}$ & $0.16 \mathrm{a}$ \\
\hline
\end{tabular}

Table 3. Effect of straw biochar application on soil enzyme activities. Different letters in each column indicate significant differences $(p<0.05)$ among the treatments for each parameter.

\begin{tabular}{|l|c|c|c|l|l|}
\hline Treatments & Number of observed OTUs & Ace & Chao1 & Shannon & Simpson \\
\hline NCK1 & $1512 \mathrm{a}$ & $2708 \mathrm{a}$ & $2253 \mathrm{a}$ & $4.95 \mathrm{ab}$ & $0.083 \mathrm{a}$ \\
\hline NCK2 & $874 \mathrm{c}$ & $1784 \mathrm{c}$ & $1434 \mathrm{c}$ & $4.79 \mathrm{~b}$ & $0.062 \mathrm{~b}$ \\
\hline NT1 & $1476 \mathrm{ab}$ & $2027 \mathrm{~b}$ & $2063 \mathrm{ab}$ & $4.86 \mathrm{~b}$ & $0.066 \mathrm{ab}$ \\
\hline NT2 & $1355 \mathrm{~b}$ & $1924 \mathrm{bc}$ & $1878 \mathrm{~b}$ & $5.16 \mathrm{a}$ & $0.044 \mathrm{c}$ \\
\hline NT3 & $1470 \mathrm{ab}$ & $2066 \mathrm{~b}$ & $2107 \mathrm{ab}$ & $4.90 \mathrm{ab}$ & $0.066 \mathrm{ab}$ \\
\hline RCK1 & $865 \mathrm{c}$ & $1280 \mathrm{c}$ & $1220 \mathrm{c}$ & $2.90 \mathrm{~d}$ & $0.265 \mathrm{a}$ \\
\hline RCK2 & $1499 \mathrm{~b}$ & $1890 \mathrm{~b}$ & $1830 \mathrm{~b}$ & $5.32 \mathrm{a}$ & $0.048 \mathrm{c}$ \\
\hline RT1 & $1090 \mathrm{c}$ & $1565 \mathrm{bc}$ & $1571 \mathrm{bc}$ & $3.65 \mathrm{c}$ & $0.234 \mathrm{ab}$ \\
\hline RT2 & $1734 \mathrm{a}$ & $2500 \mathrm{a}$ & $2486 \mathrm{a}$ & $4.39 \mathrm{~b}$ & $0.151 \mathrm{~b}$ \\
\hline RT3 & $1571 \mathrm{ab}$ & $2328 \mathrm{a}$ & $2246 \mathrm{a}$ & $5.12 \mathrm{a}$ & $0.081 \mathrm{c}$ \\
\hline
\end{tabular}

Table 4. Bacterial community abundance and diversity indices of the $16 \mathrm{~S}$ rRNA gene libraries for clustering at 97\% identity in different treatments. RCK1: R-soil in CK1; RCK2: R-soil in CK2; RT1: R-soil in T1; RT2: R-soil in T2; RT3: R-soil in T3; NCK1: N-soil in CK1; NCK2: N-soil in CK2; NT1: N-soil in T1; NT2: N-soil in T2; NT3: N-soil in T3. Different letters in each column indicate significant differences $(p<0.05)$ among the N-soil or R-soil treatments for each parameter.

order of $\mathrm{CK} 2=\mathrm{T} 3>\mathrm{CK} 1>\mathrm{T} 1>\mathrm{T} 2$. And the catalase activity in $\mathrm{CK} 2$ and $\mathrm{T} 3$ was significantly higher than $\mathrm{T} 1$ and T2. Thus, low dose of biochar addition $(2 \mathrm{~g} / \mathrm{kg}-10 \mathrm{~g} / \mathrm{kg})$ may inhibit soil catalase activity.

Effects of biochar on soil bacterial community structure. Illumina pyrosequencing was used to analyse the bacterial community diversities and phylogenetic structures in treatments with different biochar applications. The soil bacterial community richness (number of observed OTUs, ACE, and Chao1) and diversity (Shannon and Simpson) differed with the amount of biochar (Table 4). The number of observed OTUs in all treatments in N-soils and R-soils was in the order CK1 $>\mathrm{T} 1>\mathrm{T} 3>\mathrm{T} 2>\mathrm{CK} 2$ and T2 $>\mathrm{T} 3>\mathrm{CK} 2>\mathrm{T} 1>\mathrm{CK} 1$, respectively. The number of observed OTUs, ACE, and Chaol indices showed a similar trend in the treatments of N-soils or R-soils. The three indices were highest in CK1 and lowest in CK2, and they were higher in the biochar treatments than in CK2 $(p<0.05)$ in $\mathrm{N}$-soils. For the three biochar treatments, there were no differences $(p>0.05)$. Furthermore, the three indices were higher in T2 and T3 than in T1 and CK2 in the R-soils.

The Shannon index in N-soils was the highest in T2 followed by CK1, T3, T2, and CK2. The Shannon index in T2 was higher than in CK2 and T1 $(p<0.05)$. There was no significant difference in Shannon index between T2 and T3. Similarly, the Shannon index in T3 was higher than in T1 and T2 $(p<0.05)$ in R-soils, and there were no significant differences in Shannon index between T3 and CK2. The ACE and Chaol indices showed a similar pattern in R-soils, where the indices were the highest in T2 and lowest in CK1 and were different from each other $(p<0.05)$. Furthermore, the Simpson index of soil bacterial diversity was lowest in T2, which was lower than in other treatments in N-soils. The Simpson index was lowest in CK2 followed by T3, which were lower than in the other treatments $(p<0.05)$.

A Venn diagram (Figs. 1, 2) was used to evaluate the distribution of OTUs among the different treatments. Figure 1 shows that, on average, 292 OTUs containing $9.83 \%$ of all sequences were common to the $\mathrm{N}$-soil samples, which comprised $19.31 \%, 33.41 \%, 19.78 \%, 21.55 \%$, and $19.87 \%$ of OTUs in NCK1, NCK2, NT1, NT2, and NT3, respectively. Additionally, 279 OTUs containing $9.36 \%$ of all sequences were common to the R-soil samples, which comprised 32.25\%, 18.61\%, 25.60\%, 16.09\%, and 17.76\% of OTUs in RCK1, RCK2, RT1, RT2, and RT3, respectively. Figure 2 illustrates the shared or unique OTUs between the R-soil and N-soil of different treatments. The minimal overlap of OTUs in the figure indicates the great differences in bacterial communities between R-soil and N-soil despite the biochar addition.

Majority of the shared OTUs belonged to Firmicutes, Proteobacteria, and Acidobacteria. The PCoA result evidently suggested the separate bacterial communities in rhizosphere and non-rhizosphere soil samples (Fig. 3). The first axis (PCo1) explained 33.7\%, whereas the second axis (PCo2) explained $30.1 \%$. In total, the two axes explained $63.8 \%$ of species variance. This indicated that the bacterial communities in R-soil samples were similar 

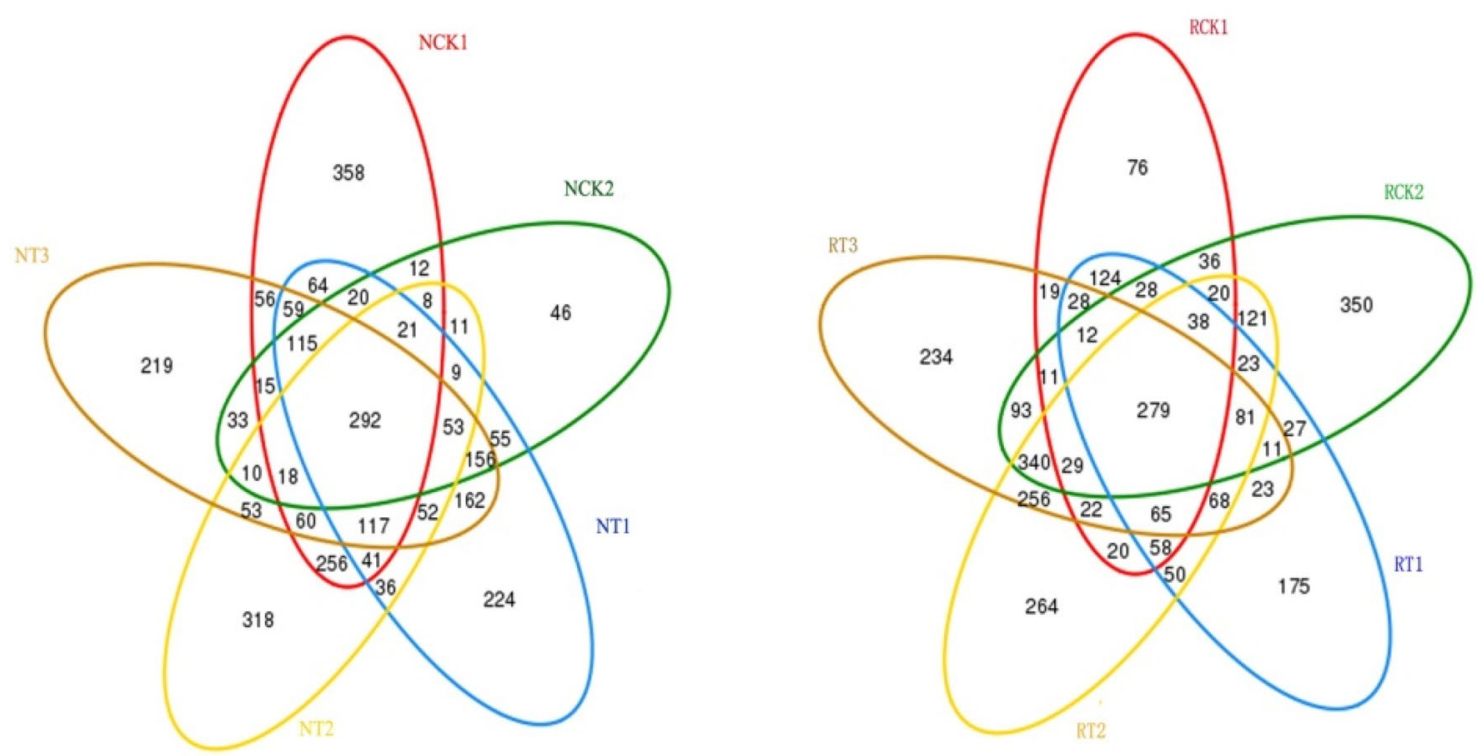

Figure 1. Venn diagrams showing the distribution of OTUs among different treatments. RCK1: R-soil in CK1; RCK2: R-soil in CK2; RT1: R-soil in T1; RT2: R-soil in T2; RT3: R-soil in T3; NCK1: N-soil in CK1; NCK2: $\mathrm{N}$-soil in CK2; NT1: N-soil in T1; NT2: N-soil in T2; NT3: N-soil in T3.
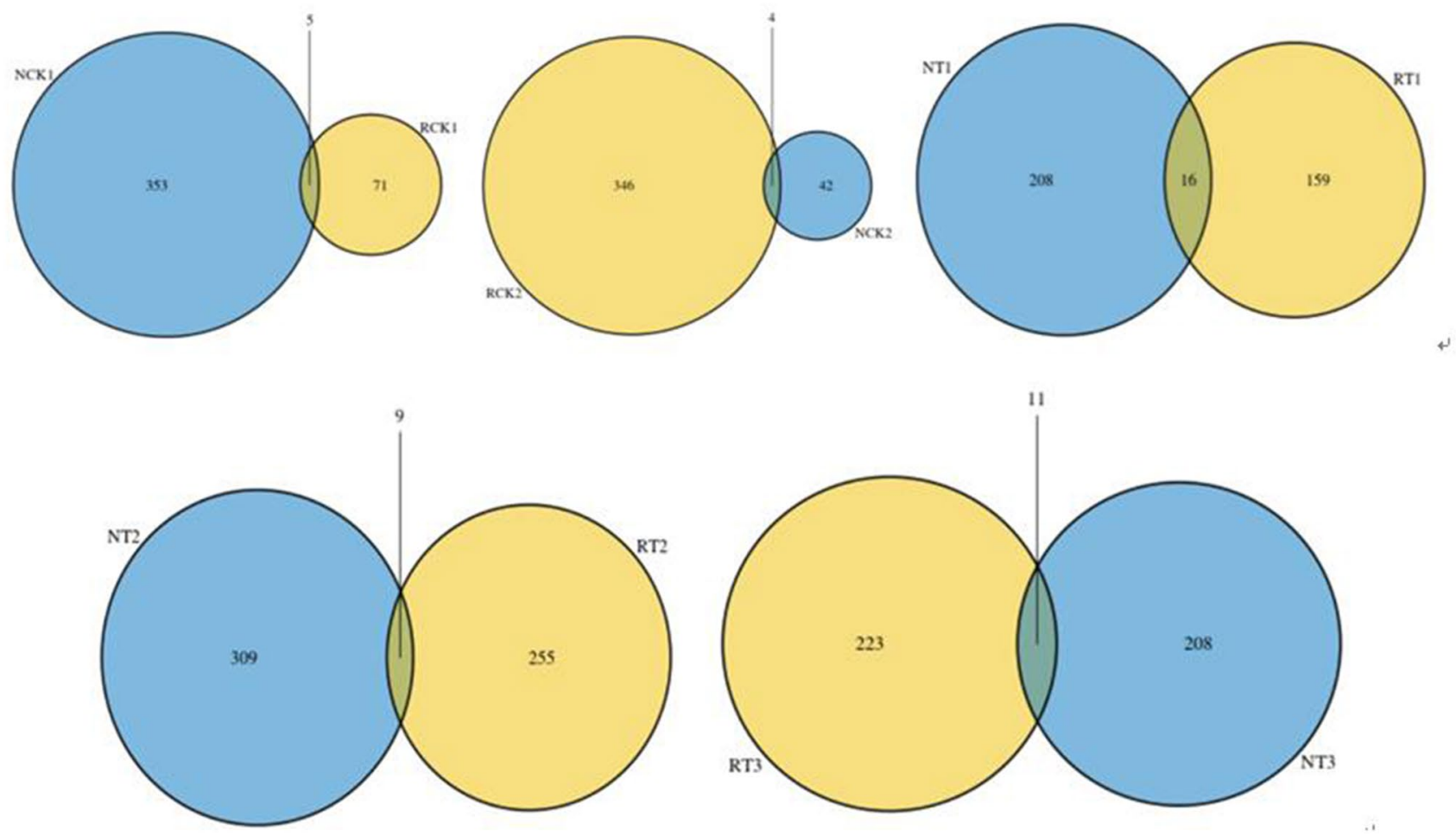

Figure 2. Venn diagrams showing the distribution of OTUs between the rhizosphere soil and bulk soil of different treatments. RCK1: R-soil in CK1; RCK2: R-soil in CK2; RT1: R-soil in T1; RT2: R-soil in T2; RT3: R-soil in T3; NCK1: N-soil in CK1; NCK2: N-soil in CK2; NT1: N-soil in T1; NT2: N-soil in T2; NT3: N-soil in T3.

and clustered in one group, whereas communities were similar in N-soil samples and also clustered in another group. And the PERMANOVA test based on the Bray-Curtis distance measures showed that the bacterial community structure was significantly (PERMANOVA; $p=0.019$ ) different between these two clusters grouped by $\mathrm{R}$-soil and $\mathrm{N}$-soil in all treatments. It was further confirmed that the root exudates and rhizosphere environment had important effects on soil bacterial community structure. 


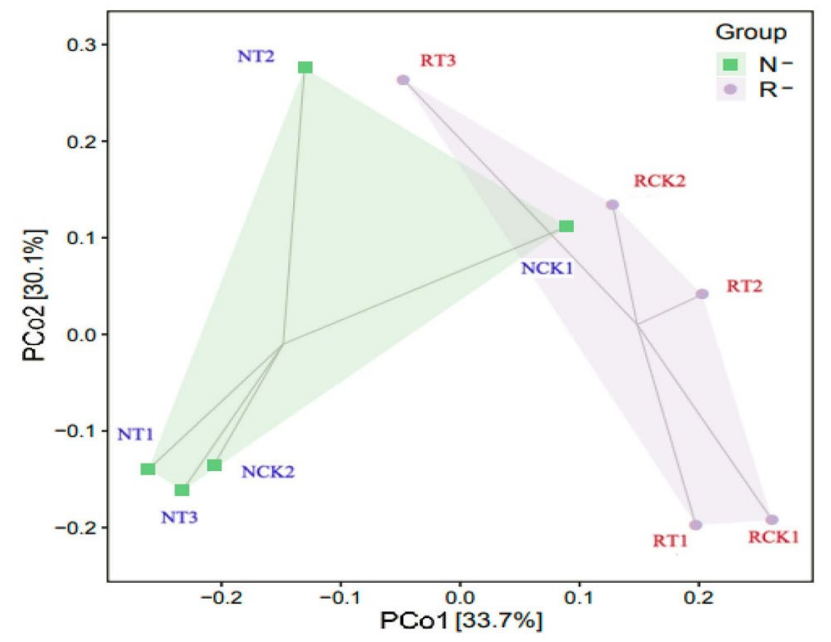

Figure 3. PCoA plot of different soil samples based on Bray-Curtis distance measures. Values on PCoA axes indicate the percentages of total variation explained by each axis and the relative abundances of OUT were used as input in the analysis. RCK1: R-soil in CK1; RCK2: R-soil in CK2; RT1: R-soil in T1; RT2: R-soil in T2; RT3: R-soil in T3; NCK1: N-soil in CK1; NCK2: N-soil in CK2; NT1: N-soil in T1; NT2: N-soil in T2; NT3: N-soil in T3.

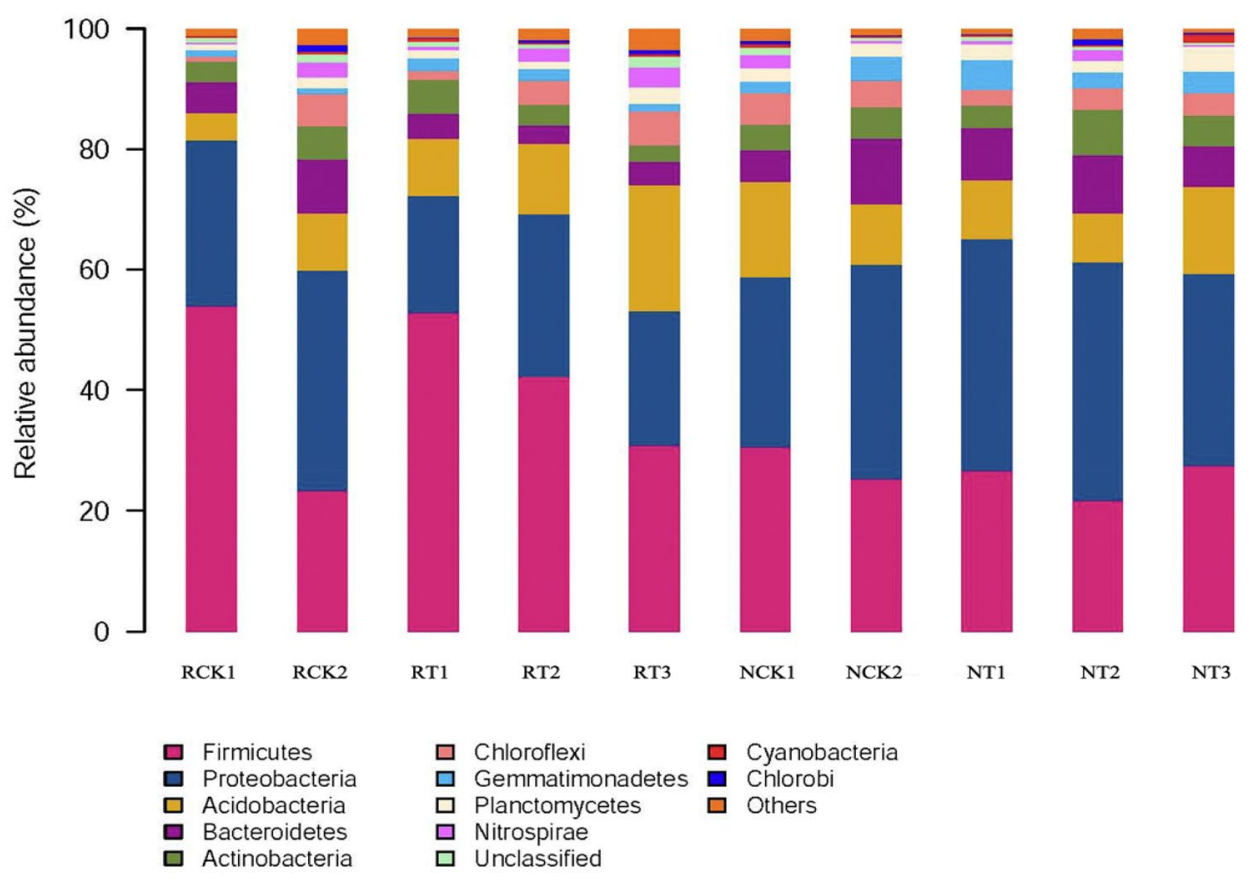

Figure 4. Relative abundance of different bacterial community structures in different treatments at the phylum level. RCK1: R-soil in CK1; RCK2: R-soil in CK2; RT1: R-soil in T1; RT2: R-soil in T2; RT3: R-soil in T3; NCK1: $\mathrm{N}$-soil in CK1; NCK2: N-soil in CK2; NT1: N-soil in T1; NT2: N-soil in T2; NT3: N-soil in T3; N-soil: nonrhizosphere soil (N-soil); R-soil: rhizosphere soil (R-soil); CK1: without fertilizer and biochar addition; CK2: with fertilizer addition and without biochar; T1: fertilizer $+0.2 \%$ biochar addition; T2 treatment: fertilizer $+1.0 \%$ biochar addition; and T3: fertilizer $+5.0 \%$ biochar addition.

The bacteria from all soil samples had similar diversity, but different abundances. The relative bacterial community abundance at the phylum level is illustrated in Fig. 4. In total, 12 phyla were identified, among which Firmicutes, Proteobacteria, and Acidobacteria were the dominant phyla in all soil samples. The relative abundance of different phyla, especially the dominant phyla, differed among different treatments. In the CK2 N-soil sample, Firmicutes accounted for $25.34 \%$ of the total bacteria, whereas it accounted for $26.61 \%, 21.74 \%$, and $27.55 \%$ of total bacteria in T1, T2, and T3, respectively. Proteobacteria, another predominant phylum, accounted for 


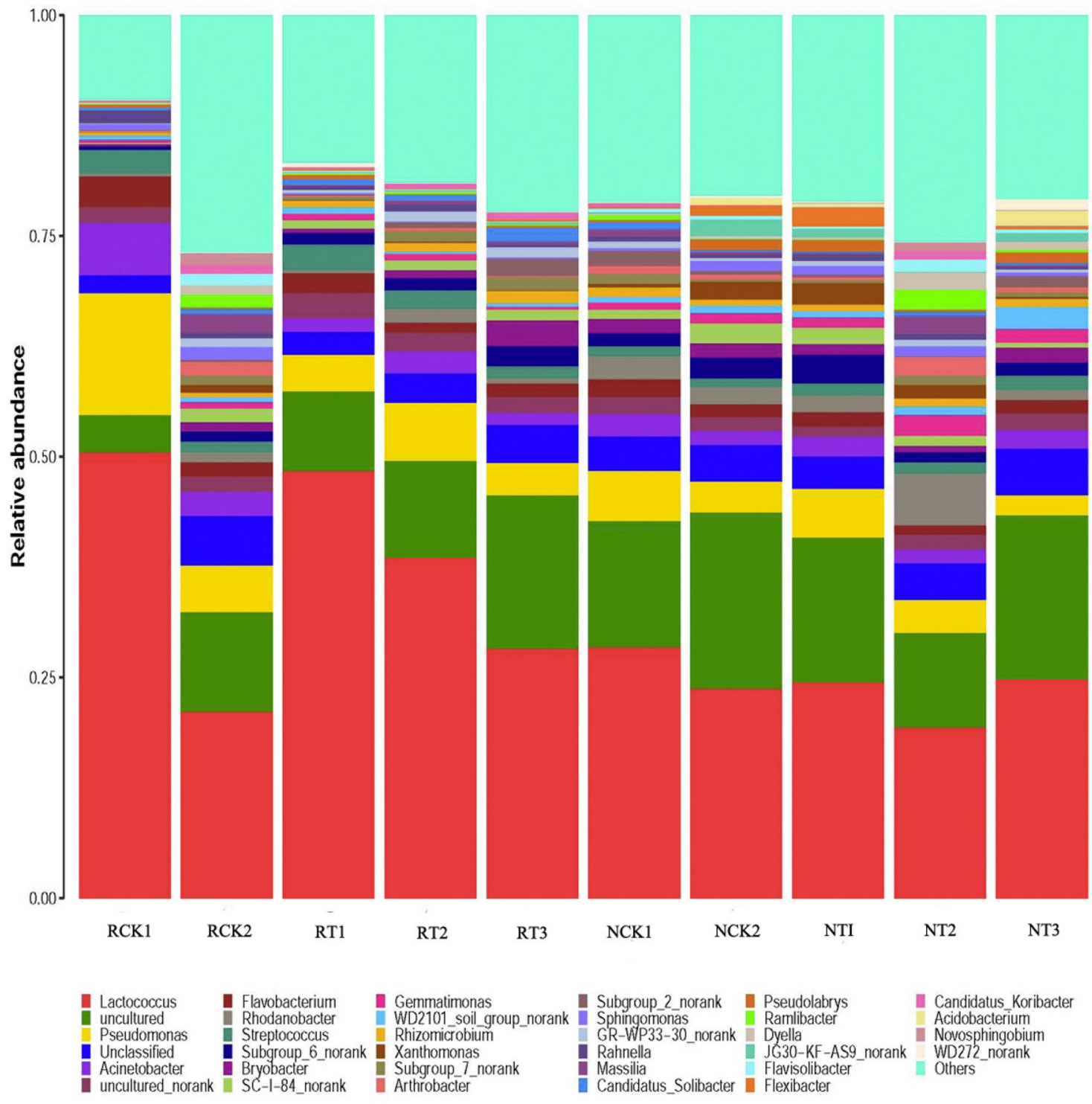

Figure 5. Relative read abundance of different bacterial community structures in different treatments at the genus level. RCK1: R-soil in CK1; RCK2: R-soil in CK2; RT1: R-soil in T1; RT2: R-soil in T2; RT3: R-soil in T3; NCK1: N-soil in CK1; NCK2: N-soil in CK2; NT1: N-soil in T1; NT2: N-soil in T2; NT3: N-soil in T3.

$35.45 \%$ of the total bacteria in CK2, and it accounted for comparatively higher proportion in T1 (38.45\%) and T2 (39.49\%), but comparatively lower proportion in T3 (31.76\%). In comparison with the Acidobacteria abundance in CK2 (10.02\%), the abundance was clearly higher in T3 (14.42\%), and lower in T1 (9.87\%) and T2 (8.18\%).

In the R-soil samples, the abundance of Firmicutes in CK2 accounted for $23.39 \%$ of the total bacteria at the phylum level, which was evidently lower than T1 (52.86\%), T2 (42.26\%), and T3 (30.79\%). The abundance of Proteobacteria, another predominant phylum, accounted for $36.41 \%$ of the total bacteria in CK2, which was higher than T1 (19.41\%), T2 (27.02\%), and T3 (22.38\%). The abundance of Acidobacteria was high in T2 (11.70\%) and T3 (20.87\%), and comparatively lower in T1 (9.42\%) and CK2 (9.61\%).

Further analysis investigated the relative bacterial community abundance at the genus level (Fig. 5). In total, 496 genera were recorded in all soil samples, among which Lactococcus, uncultured, Pseudomonas, uncultured_ norank, unclassified, and Flavobacterium were the dominant genera. In N-soil samples, Lactococcus accounted for $23.76 \%$ of the total bacteria in CK2, and it accounted for comparatively higher proportion in T1 (24.51\%) and T3 (24.82\%), and a lower proportion in T2 treatment (19.41\%). In R-soil samples, Lactococcus accounted for $21.13 \%$ of the total bacteria in CK2, and comparatively higher proportion in T1 (48.43\%), T2 (38.64\%), and T3 (28.34\%).

The analysis of microbial community heatmap and similarity tree analysis for multiple samples identified the similarities and differences among the 10 bacterial community structures (Figs. 6, 7). The results showed that the communities were divided into two clusters based on similar community structure. CK2, T1, and T3 of $\mathrm{N}$-soil were clustered together, whereas CK2, T2, and T3 of R-soil were clustered together, which also implied approximately similar bacterial community structure. And the high dose of biochar $(50 \mathrm{~g} / \mathrm{kg})$ decreased the similarity of soil bacterial community structure in rhizosphere compared with those in non-rhizosphere soil. 


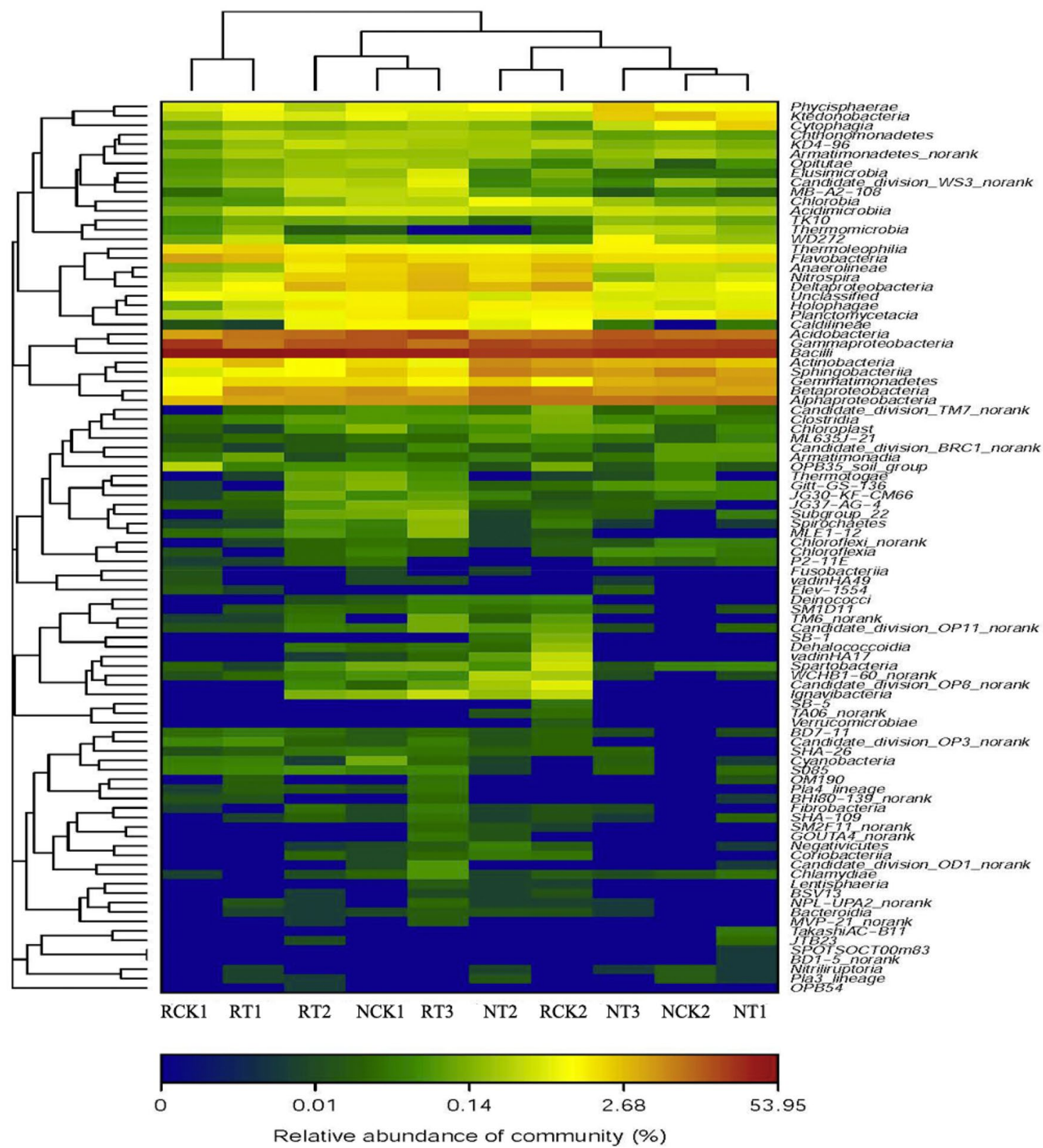

Figure 6. Species abundance clustering diagram of soil bacteria in different treatments at the genus level. RCK1: R-soil in CK1; RCK2: R-soil in CK2; RT1: R-soil in T1; RT2: R-soil in T2; RT3: R-soil in T3; NCK1: $\mathrm{N}$-soil in CK1; NCK2: N-soil in CK2; NT1: N-soil in T1; NT2: N-soil in T2; NT3: N-soil in T3.

Additionally, the two clusters were well separated from each other, suggesting a clear distinction between the bacterial community structures.

\section{Discussion}

The objective of this study was to evaluate the effect of straw biochar addition on tobacco growth, soil properties, and rhizosphere bacterial communities, which might be related to the dose effect of biochar. The obtained results suggested that biochar had an important effect on tobacco growth and a suitable dose of biochar (2-10 g/ $\mathrm{kg}$ ) could promote tobacco growth, but a higher dose $(50 \mathrm{~g} / \mathrm{kg})$ could inhibit growth thus, supporting the results of previous studies ${ }^{40-42}$. Biochar application can improve soil $\mathrm{pH}$ and soil physicochemical properties ${ }^{43,44}$, and maximum nutrients can be desorbed from biochar and get readily absorbed into plants, which can subsequently promote tobacco growth. In the present study, our results showed that biochar addition increased few soil parameters, such as soil $\mathrm{pH}$, soil organic carbon, and available nitrogen, phosphorus, and potassium. These results are consistent with the results of previous studies ${ }^{45,46}$. The improvement in soil nutrient contents by biochar addition is a direct impact of biochar, which can be attributed to its high nutritional value ${ }^{47,48}$. The application of biochar has other indirect influences on plant growth, such as increasing nutrient retention and nutrient use efficiency and reducing the nutrient leaching ${ }^{49}$. Therefore, biochar application could improve the overall crop 


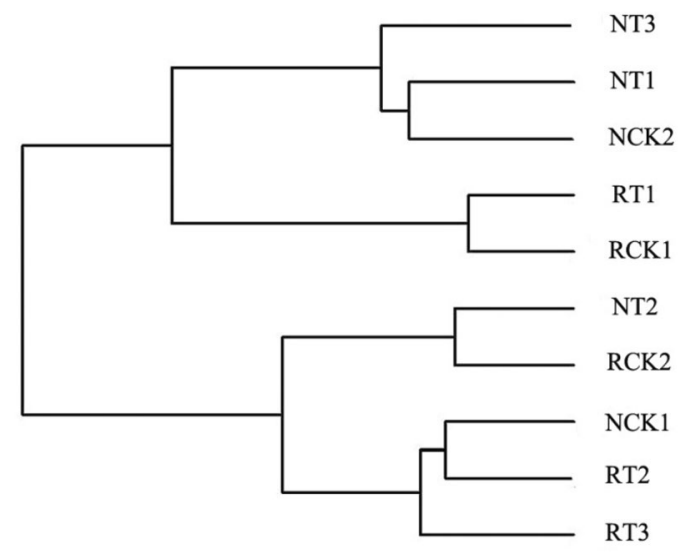

0.01

Figure 7. Clustering tree of soil bacteria in the different treatments. RCK1: R-soil in CK1; RCK2: R-soil in CK2; RT1: R-soil in T1; RT2: R-soil in T2; RT3: R-soil in T3; NCK1: N-soil in CK1; NCK2: N-soil in CK2; NT1: N-soil in T1; NT2: N-soil in T2; NT3: N-soil in T3.

growth by affecting nutrient uptake ${ }^{50,51}$. A recent meta-analysis study showed that variations in plant growth and productivity response had a pooled mean of $16.0 \pm 1.3 \%$ and a range of $-31.8 \%$ to $974 \%$ under different biochar or/and soil conditions ${ }^{52}$.

In contrast, tobacco growth was inhibited by the addition of a high dose of biochar $(40 \mathrm{mg} / \mathrm{kg})$ in the current study (Table 1). There are also some reports of negative or insignificant effects of biochar on crop growth and yield. For example, Liu et al. $(2013)^{53}$ found that crop productivity tended to decrease with increasing biochar application rates $\left(>40 \mathrm{t} \mathrm{ha}^{-1}\right)$. Excessive amounts of biochar can inhibit crop growth and are related to $\mathrm{N}$ immobilization caused by high volatile content, toxic or harmful substance content, and reduced nutrient uptake and crop growth ${ }^{54}$. Heavy metals in the rice straw biochar were all below the threshold of heavy metals in biochar as reported by the International Biochar Initiative (IBI) and the European Biochar Certificate (EBC) ${ }^{55}$. The N immobilization maybe therefore be the limiting factor in tobacco growth. Nitrogen limitation may inhibit tobacco growth due to high doses of biochar, as the availability of $\mathrm{N}$ decreases because of $\mathrm{N}$ immobilization by microbial biomass at high C:N ratios, although other growth-limiting factors may be responsible for growth limitation as well $^{56,57}$. The high dose of biochar application could improve the base cation content of $\mathrm{K}$ and soil pH (Table 2). The available K contributed most to the osmotic pressure and high $\mathrm{pH}$ which negatively affected plant growth ${ }^{58}$.

Soil enzyme activity is a key indicator of microbial function in nutrient retention and conversion associated with soil fertility. Previous studies have raised considerable doubts about the effect of biochar addition on the activity of soil hydrolases ${ }^{18,59}$, which may likely be associated with the biochar types and soil properties ${ }^{60,61}$. In this study, the addition of biochar increased the soil enzymatic activity of urease, invertase, and acid phosphatase, which was in accordance with the findings of previous studies ${ }^{62,63}$. Our results suggest that biochar might stimulate soil enzymic activity and affect bacterial community abundance via increasing soil organic carbon and available nitrogen, which is consistent with a previous study ${ }^{64}$. Large amounts of biochar addition $(50 \mathrm{~g} / \mathrm{kg}$ ) significantly improved the SOC and available N contents (Tables 1,3$)$, which can be partly explained by the increase in the activity of invertase and urease. Furthermore, biochar has the capacity to absorb a variety of organic and inorganic molecules and inhibit certain soil enzymes or their substrates by adsorbing onto or blocking the reaction sites ${ }^{17,18}$, which may explain our results for catalase activities. Thus, the biochar amendment may contribute to maintaining or enhancing the enzymatic activity of $\mathrm{C}-, \mathrm{N}-$, and P-cycling in the soil.

According to Hammer et al. $(2014)^{65}$, biochar presents a complex matrix for the diversity of soil microorganisms and the source of nutrients. In this study, biochar addition increased the N-soil bacterial diversity to a degree. Different doses of biochar showed different effects on soil bacterial abundance in this study. The medium biochar addition $(10 \mathrm{~g} / \mathrm{kg}$, NT2) had a better effect on improving soil bacterial abundance, possibly because less $(2 \mathrm{~g} / \mathrm{kg})$ or large $(50 \mathrm{~g} / \mathrm{kg})$ amounts of biochar contains insufficient or excessive basic ions that are not suitable for soil microbial growth ${ }^{54}$. This result was consistent with the previous studies that lower doses of biochar had positive effects but higher doses of biochar caused toxicity and inhibition ${ }^{66,67}$. The biochar addition showed different effect on soil bacteria in rhizosphere in this study, that the richness of bacteria was increased, but the diversity decreased with the biochar addition (Table 4), which was consistent with the previous studies ${ }^{68}$. And the relative abundance of different bacterial community structures at the phylum or genus level (Figs. 3, 4) both convinced that the bacteria community in R-soil were sensitive to biochar addition than those in N-soil. The biochar nutrients, associated with biochar-influenced soil environment, can probably stimulate root growth (Table1) with the biochar addition. In turn, the carbon products secreted by facilitated growing roots, which are preferential nutrients and energy for microbial metabolism, can also affect microbial community in the rhizosphere soil ${ }^{69}$.

In the present study, the high-throughput sequencing analysis of Miseq indicated that biochar addition could significantly influence soil bacterial community structure either in rhizosphere or non-rhizosphere of tobacco (Table 4). Ace and Chaol indices are indicators of microbial richness, whereas Shannon-Weiner and 
Simpson indices reflect microbial diversity ${ }^{70}$. Previous reports have shown that biochar may affect soil bacterial communities by improving the soil physico-chemical properties (e.g. sorption, $\mathrm{pH}$, chemical properties, and habitats $)^{26,71,72}$. Our results showed that biochar addition increased soil $\mathrm{pH}$, organic carbon, and available soil nutrients. Besides, physical properties of biochar, such as high nanoporosity and large surface area could improve water retention and aeration in soil; thereby providing a better habitat for the growth of soil bacteria, which may lead to changes in the bacterial community structure ${ }^{16,72}$. The changes in chemical properties of soil after biochar addition may also explain the changes in bacterial communities ${ }^{73}$. Furthermore, the OTUs, as well as Ace, Chao1, Shannon-Weiner, and Simpson indices differed between rhizosphere and non-rhizosphere, and they differed with the different biochar doses. Rhizosphere is an important site for nutrient and energy exchange between plants and soil microbes, and the Root exudates are speculated to be the main driving force for growth of soil bacteria in different soils ${ }^{74}$. Plants can alter soil bacterial richness, diversity, structure, and function by modifying their root exudates ${ }^{75}$ Environmental changes were found to greatly affect the quantity and quality of root exudates ${ }^{76}$. These could be the reasons for the differences between rhizosphere and non-rhizosphere bacterial communities ${ }^{77}$.

In the case of the bacterial community composition, Firmicutes, Proteobacteria, Acidobacteria, Bacteroidetes, and Actinobacteria were the predominant ( $>2 \%)$ phyla in all treatments (Fig. 3). Proteobacteria occupied the highest proportions (28.17-38.45\%) of the bacterial sequences in N-soil, but Firmicutes occupied the highest proportions (23.39-53.98\%) in R-soils. The proportion of Firmicutes was increased, but the proportions of Proteobacteria and Bacteroidetes were decreased in the R-soil compared with that in the N-soil under the biochar addition. This could be influenced by synergistic effects, such as co-metabolism or syntrophy of these bacteria, or because of their similar response patterns to biological, chemical, or physical variables, i.e., presence of a similar niche ${ }^{78}$. Taketani et al. $(2013)^{79}$ found that the phylum Proteobacteria, which colonizes nutrient-rich environments, was the most predominant taxa in $\mathrm{N}$-soil samples. It has been reported that Actinobacteria are often associated with the degradation of recalcitrant polymers, and thus, this phylum is considered ecologically important for decomposing organic matter in the soil. Meanwhile, at the genus level, the bacterial abundance was also distinct between R-soil and N-soil in biochar amended samples (Fig. 4). Furthermore, the PCoA result in this study showed significant differences in bacterial communities between the R-soil and N-soils despite the biochar addition, suggesting that the communities were highly influenced by the root exudates and rhizosphere environment. In previous studies, the analysis of the genetic relationships between the plants and the microbial communities showed that the bacterial compositions in the $\mathrm{N}$-soils and R-soils were completely different, which might be a consequence of the action of tobacco root exudates ${ }^{80,81}$. Therefore, the effect of biochar on rhizosphere bacterial communities is a complex process. The inner mechanisms of the microorganisms still need elucidation through long-term experiments.

\section{Conclusions}

Straw biochar application could affect tobacco agronomic traits and biomass to a certain degree. Low (2 g/kg) and moderate $(10 \mathrm{~g} / \mathrm{kg})$ doses of biochar application had positive effects on tobacco agronomic traits, but growth was inhibited at high doses $(50 \mathrm{~g} / \mathrm{kg}$ ). This capacity was associated with changes in soil $\mathrm{pH}$, SOC, and related properties. Under biochar treatment, soil urease, invertase, and acid phosphatase activities were increased but catalase activity was decreased or remained unchanged with the increased biochar amendment.

Straw biochar addition had a significant effect on the bacterial community structure either in rhizosphere and non-rhizosphere soil. Firmicutes, Proteobacteria, Acidobacteria, Bacteroidetes, and Actinobacteria were the predominant $(>2 \%)$ phyla in all soil treatments. Proteobacteria occupied the highest proportions (28.17-38.45\%) of the bacterial sequences in N-soil, but Firmicutes occupied the highest proportions (23.39-53.98\%) in R-soils. Substantial differences in the bacterial communities between R-soil and $\mathrm{N}$-soil were found despite the biochar addition.

In treatments with low and moderate dose of biochar, soil bacterial community structure of rhizosphere and non-rhizosphere soil, was similar to the control treatment soil. But high dose of biochar $(50 \mathrm{~g} / \mathrm{kg})$ reduced such benefits especially in rhizosphere. So, the response of the bacterial community to straw biochar is a complex process affected by the biochar dosage and the root system, which would then drive the process of nutrient transformation and hence affect the growth of tobacco. However, the results of this study were based on a pot experiment over one growing season. In the future, long-term observations and field positioning experiments treated with straw biochar should be carried out to elucidate the effects of biochar on the soil micro-ecological environment, crop growth, and their inner mechanisms.

Received: 9 March 2021; Accepted: 1 October 2021

Published online: 20 October 2021

\section{References}

1. Lehmann, J. \& Joseph, S. Biochar for environmental management: An introduction. In Biochar for Environmental Management (eds Lehmann, J. \& Joseph, S.) 33-46 (Routledge, 2015).

2. Wiedner, K. et al. Chemical modification of biomass residues during hydrothermal carbonization-What makes the difference, temperature or feedstock?. Org. Geochem. 54, 91-100 (2013).

3. Ronsse, F., Van Hecke, S., Dickinson, D. \& Prins, W. Production and characterization of slow pyrolysis biochar: Influence of feedstock type and pyrolysis conditions. Gcb. Bioenergy. 5, 104-115 (2013).

4. Van Zwieten, L. et al. Effects of biochar from slow pyrolysis of papermill waste on agronomic performance and soil fertility. Plant Soil. 327(1-2), 235-246 (2010).

5. Agrafioti, E., Bouras, G., Kalderis, D. \& Diamadopoulos, E. Biochar production by sewage sludge pyrolysis. J. Anal. Appl. Pyrolysis. 101, 72-78 (2013).

6. Cantrell, K. B., Hunt, P. G., Uchimiya, M., Novak, J. M. \& Ro, K. S. Impact of pyrolysis temperature and manure source on physicochemical characteristics of biochar. Bioresour. Technol. 107, 419-428 (2012). 
7. Pandey, V., Patel, A. \& Patra, D. D. Biochar ameliorates crop productivity, soil fertility, essential oil yield and aroma profiling in basil (Ocimumbasilicum L.). Ecol. Eng. 90, 361-366 (2016).

8. Liu, X. et al. Biochar's effect on crop productivity and the dependence on experimental conditions-a meta-analysis of literature data. Plant Soil. 373, 583-594 (2013).

9. Ullah, S. et al. Biochar coupled with contrasting nitrogen sources mediated changes in carbon and nitrogen pools, microbial and enzymatic activity in paddy soil. J. Saudi. Chem. Soc. 24, 835-849 (2020).

10. Atkinson, C. J., Fitzgerald, J. D. \& Hipps, N. A. Potential mechanisms for achieving agricultural benefits from biochar application to temperate soils: A review. Plant Soil 337(1-2), 1-18 (2010).

11. Streubel, J. D. et al. Influence of contrasting biochar types on five soils at increasing rates of application. Soil. Sci. Soc. Am. J. 75(4), $1402-1413$ (2011).

12. Tammeorg, P. et al. Short-term effects of biochar on soil properties and wheat yield formation with meat bone meal and inorganic fertiliser on a boreal loamy sand. Agric. Ecosyst. Environ. 191, 108-116 (2014).

13. Ameloot, N. et al. Mineralization and microbial activity in four biochar field experiments several years after incorporation. Soil. Biol. Biochem. 78, 195-203 (2014).

14. Chan, K. Y., van Zwieten, L., Meszaros, I., Downie, A. \& Joseph, S. Agronomic values of green waste biochar as a soil amendment. Aust. J. Soil Res. 45, 629-634 (2007).

15. De Tender, C. et al. Biological, physicochemical and plant health responses in lettuce and strawberry in soil or peat amended with biochar. Appl. Soil Ecol. 107, 1-12 (2016).

16. De Tender, C. et al. Dynamics in the strawberry rhizosphere microbiome in response to biochar and Botrytis cinereal leaf infection. Front Microbiol. 7, 2062 (2016).

17. Bailey, V. L., Fansler, S. J., Smith, J. L. \& Bolton, H. Jr. Reconciling apparent variability in effects of biochar amendment on soil enzyme activities by assay optimization. Soil Biol. Biochem. 43(2), 296-301 (2011).

18. Zhang, Y., Xiang, Y., Jing, Y. \& Zhang, R. Biochar amendment effects on the activities of soil carbon, nitrogen, and phosphorus hydrolytic enzymes: A meta-analysis. Environ. Sci. Pollut. Res. Int. 26(22), 22990-23001 (2019).

19. Xu, H. J. et al. Biochar impacts soil microbial community composition and nitrogen cycling in an acidic soil planted with rape. Environ. Sci. Technol. 48(16), 9391-9399 (2014).

20. Prayogo, C., Jones, J. E., Baeyens, J. \& Bending, G. D. Impact of biochar on mineralisation of C and N from soil and willow litter and its relationship with microbial community biomass and structure. Biol. Fert. Soils. 50(4), 695-702 (2014).

21. Grossman, J. M. et al. Amazonian anthrosols support similar microbial communities that differ distinctly from those extant in adjacent, unmodified soils of the same mineralogy. Microb. Ecol. 60(1), 192-205 (2010).

22. Rutigliano, F. A. et al. Effect of biochar addition on soil microbial community in a wheat crop. Eur. J. Soil Biol. 60, 9-15 (2014).

23. Chen, J. et al. Biochar soil amendment increased bacterial but decreased fungal gene abundance with shifts in community structure in a slightly acid rice paddy from Southwest China. Appl. Soil. Ecol. 71, 33-44 (2013).

24. Xu, N., Tan, G., Wang, H. \& Gai, X. Effect of biochar additions to soil on nitrogen leaching, microbial biomass and bacterial community structure. Eur. J. Soil Biol. 74, 1-8 (2016).

25. Praeg, N., Pauli, H. \& Illmer, P. Microbial diversity in bulk and rhizosphere soil of ranunculus glacialis along a high-alpine altitudinal gradient. Front. Microbiol. 10, 1429 (2019).

26. Rousk, J. et al. Soil bacterial and fungal communities across a pH gradient in an arable soil. ISME. J. 4(10), 1340-1351 (2010).

27. Jaiswal, A. K., Elad, Y., Graber, E. R., Cytryn, E. \& Frenkel, O. Soil-borne disease suppression and plant growth promotion by biochar soilamendments and possible mode of action. Acta Hortic. 1207, 69-76 (2018).

28. Sinha, S. et al. Rhizosphere soil microbial index of tree species in a coal mining ecosystem. Soil Biol. Biochem. 41(9), 1824-1832 (2009).

29. Kowalchuk, G. A., Stienstra, A. W., Heilig, G. H. J., Stephen, J. R. \& Woldendorp, J. W. Molecular analysis of ammonia-oxidising bacteria in soil of successional grasslands of the Drentsche A (the Netherlands). FEMS Microbiol. Ecol. 31, 207-215 (2000).

30. Zhang, J. X., Zhang, Z. F., Shen, G. M., Rui, W. \& Zhang, J. G. Growth performance, nutrient absorption of tobacco and soil fertility after straw biochar application. Int. J. Agric. Biol. 18(5), e7576 (2016).

31. Olsen, S. R. \& Sommers, L. E. Phosphorus. In Methods of Soil Analysis: Part 2 Chemical and Microbiological Properties (ed. Page, A. L.) 403-430 (Soil Science Society of America Inc., 1982).

32. Sparks, D. L. et al. Methods of Soil Analysis Part 3: Chemical methods (Soil Science Society of America and American Society of Agronomy, 1996).

33. Arshad, M. A. \& Coen, G. M. Characterization of soil quality: Physical and chemical criteria. Am. J. Altern. Agric. 7, 25-32 (1992).

34. Li, F. M. Analysis of soil enzyme activity. In Experimental Techniques in Agriculture Microbiology (eds Li, F. M. et al.) (Chinese Agriculture Press, 1996).

35. Guan, S. Y. Soil Enzymes and Research Methods (Agricultural press, 1986) (in Chinese).

36. Xu, G. H. \& Zheng, H. Y. Handbook of Soil Microbiology Analysis Method (Chinese Agriculture Press, 1986).

37. Caporaso, J. G. et al. QIIME allows analysis of high-throughput community sequencing data. Nat. Methods 7(5), 335 (2010).

38. Edgar, R. C. UPARSE: Highly accurate OTU sequences from microbial amplicon reads. Nat. Met. 10(10), 996 (2013).

39. Magoč, T. \& Salzberg, S. L. FLASH: Fast length adjustment of short reads to improve genome assemblies. Bioinformatics 27(21), 2957-2963 (2011).

40. Zhang, L., Sun, X. Y., Tian, Y. \& Gong, X. Q. Biochar and humic acid amendments improve the quality of composted green waste as a growth medium for the ornamental plant Calathea insignis. Sci. Hortic. 176, 70-78 (2014).

41. Ahmad, M. T., Asghar, H. N., Saleem, M., Khan, M. Y. \& Zahir, Z. A. Synergistic effect of rhizobia and biochar on growth and physiology of maize. Agron. J. 107(6), 2327-2334 (2015).

42. Carter, S., Shackley, S., Sohi, S., Suy, T. \& Haefele, S. The impact of biochar application on soil properties and plant growth of pot grown lettuce (Lactuca sativa) and cabbage (Brassica chinensis). Agronomy 3(2), 404-418 (2013).

43. Robertson, S. J., Rutherford, P. M., Lopez-Gutierrez, J. C. \& Massicotte, H. B. Biochar enhances seedling growth and alters root symbioses and properties of sub-boreal forest soils. Can. J. Soil. Sci. 92(2), 329-340 (2012).

44. Biederman, L. A. \& Harpole, W. S. Biochar and its effects on plant productivity and nutrient cycling: A meta-analysis. GCB Bioenergy. 5(2), 202-214 (2013).

45. Zhang, G. L. et al. Criteria for establishment of soil family and soil series in Chinese Soil Taxonomy. Acta Pedol. Sin. 50(4), 826-830 (2013) (in Chinese with English abstract).

46. Zhou, H. et al. Changes in microbial biomass and the metabolic quotient with biochar addition to agricultural soils: A Metaanalysis. Agric. Ecosyst. Environ. 239, 80-89 (2017).

47. Lei, O. \& Zhang, R. Effects of biochars derived from different feedstocks and pyrolysis temperatures on soil physical and hydraulic properties. J. Soil. Sediment. 13(9), 1561-1572 (2013).

48. Zheng, J. et al. Biochar compound fertilizer increases nitrogen productivity and economic benefits but decreases carbon emission of maize production. Agric. Ecosyst. Environ. 241, 70-78 (2017).

49. El-Naggar, A. et al. Influence of soil properties and feedstocks on biochar potential for carbon mineralization and improvement of infertile soils. Geoderma 332, 100-108 (2018).

50. Li, Y. et al. Phytotoxicity assessment on corn stover biochar, derived from fast pyrolysis, based on seed germination, early growth, and potential plant cell damage. Environ. Sci. Pollut. Res. 22(12), 9534-9543 (2015). 
51. Joseph, S. et al. Effects of enriched biochars containing magnetic iron nanoparticles on mycorrhizal colonisation, plant growth, nutrient uptake and soil quality improvement. Pedosphere 25(5), 749-760 (2015).

52. Dai, Y., Zheng, H., Jiang, Z. \& Xing, B. Combined effects of biochar properties and soil conditions on plant growth: A meta-analysis. Sci. Total Environ. 713, 136635 (2020).

53. Liu, X. et al. Biochar's effect on crop productivity and the dependence on experimental conditions-a meta-analysis of literature data. Plant Soil 373, 583-594 (2013).

54. Ding, Y. et al. Biochar to improve soil fertility: A review. Agron. Sustain 36, 36 (2016).

55. International Biochar Initiative (IBI). Standardized product definition an-d product testing guidelines for biochar that is used in soil (aka IBI Biochar Standards) Version 2.1. Westerville OH: International BiocharInitiative. http://www.biochar-international. org/characterizationstandard (2015).

56. Kolton, M. et al. Impact of biochar application to soil on the root-associated bacterial community structure of fully developed greenhouse pepper plants. Appl. Environ. Microbiol. 77(14), 4924-4930 (2011).

57. Lehmann, J. et al. Soilfertility and Production Potential, Amazonian Dark Earths 105-124 (Springer, 2003).

58. Buss, W., Graham, M. C., Shepherd, J. G. \& Mašek, O. Risks and benefits of marginal biomass-derived biochars for plant growth. Sci. Total Environ. 569-570, 496-506 (2016).

59. Sigua, G. C., Novak, J. M., Watts, D. W., Szögi, A. A. \& Shumaker, P. D. Impact of switchgrass biochars with supplemental nitrogen on carbon-nitrogen mineralizationin highly weathered Coastal Plain Ultisols. Chemosphere 145, 135-141 (2016).

60. Zhu, X. M., Chen, B. L., Zhu, L. Z. \& Xing, B. S. Effects and mechanisms of biochar-microbe interactions in soil improvement and pollution remediation: A review. Environ. Pollut. 227, 98-115 (2017).

61. Nie, Y. X. et al. Impact of sugarcane bagasse-derived biochar on heavy metal availability and microbial activity: A field study. Chemosphere 200, 274-282 (2018)

62. Elzobair, K. A., Stromberger, M. E., Ippolito, J. A. \& Lentz, R. D. Contrasting effects of biochar versus manure on soil microbial communities and enzyme activities in an Aridisol. Chemosphere 142, 145-152 (2016).

63. Wang, X. et al. Maize biochar addition rate influences soil enzyme activity and microbial community composition in a fluvo-aquic soil. Appl. Soil. Ecol. 96, 265-272 (2015).

64. Gomez, J. D., Denef, K., Stewart, C. E., Zheng, J. \& Cotrufo, M. F. Biochar addition rate influences soil microbial abundance and activity in temperate soils. Eur. J. Soil Sci. 65, 28-39 (2014).

65. Hammer, E. C. et al. A mycorrhizal fungus grows on biochar and captures phosphorus from its surfaces. Soil Biol. Biochem. 77, $252-260$ (2014).

66. Jaiswal, A. K., Elad, Y., Graber, E. R. \& Frenkel, O. Rhizoctonia solani suppression and plant growth promotion in cucumber as affected by biochar pyrolysis temperature, feedstock and concentration. Soil Biol. Biochem. 69, 110-118 (2014).

67. Kammann, C. \& Graber, E. R. Biochar effects on plant ecophysiology. In Biochar for Environmental Management: Science and Technology (eds Lehmann, J. \& Joseph, S.) 391-419 (Earthscan Books Ltd, 2015).

68. Koltonb, M., Graber, E. R., Tsehansky, L., Elad, Y. \& Cytryn, E. Biochar-stimulated plant performance is strongly linked to microbial diversity and metabolic potential in the rhizosphere. New Phytol. 213, 1393-1404 (2017).

69. Dai, Z. et al. Sensitive responders among bacterial and fungal microbiome to pyrogenic organic matter (biochar) addition differed greatly between rhizosphere and bulk soils. Sci. Rep. 6, 36101 (2016).

70. Zhu, D., Tanabe, S. H., Yang, C., Zhang, W. \& Sun, J. Bacterial community composition of South China Sea sediments through pyrosequencing-based analysis of 16S rRNA genes. PLoS ONE 8(10), e78501 (2013).

71. Hale, L., Luth, M. \& Crowley, D. Biochar characteristics relate to its utility as an alternative soil inoculum carrier to peat and vermiculite. Soil Biol. Biochem. 81, 228-235 (2015).

72. Thies, J. E. \& Rillig, M. C. Characteristics of biochar: Biological properties. In Biochar for Environmental Management: Science and Technology (eds Lehmann, J. \& Joseph, S.) 85-105 (Earthscan, 2009).

73. Fan, S., Zuo, J. \& Dong, H. Changes in soil properties and bacterial community composition with biochar amendment after six years. Agronomy 10(5), 746 (2020).

74. Liu, F. D., Mo, X., Kong, W. J. \& Song, Y. Soil bacterial diversity, structure, and function of Suaeda salsa in rhizosphere and nonrhizosphere soils in various habitats in the Yellow River Delta, China. Sci. Total Environ. 740, 140144 (2020).

75. Yang, W. et al. Alterations in soil bacterial community in relation to Spartina alterniflora Loisel. invasion chronosequence in the eastern Chinese coastal wetlands. Appl. Soil Ecol. 135, 38-43 (2019).

76. Gargallo-Garriga, A. et al. Root exudate metabolomes change under drought and show limited capacity for recovery. Sci. Rep. 8, 12696 (2018).

77. Nielsen, S. et al. Comparative analysis of the microbial communities in agricultural soil amended with enhanced biochars or traditional fertilisers. Agric. Ecosyst. Environ. 191, 73-82 (2014).

78. Taketani, R. G. et al. Bacterial community composition of anthropogenic biochar and Amazonian anthrosols assessed by $16 \mathrm{~S}$ rRNA gene 454 pyrosequencing. Antonie Van Leeuwenhoek 104(2), 233-242 (2013).

79. O'neill, B. et al. Bacterial community composition in Brazilian Anthrosols and adjacent soils characterized using culturing and molecular identification. Microb. Ecol. 58(1), 23-35 (2009).

80. Steer, J. \& Harris, J. A. Shifts in the microbial community in rhizosphere and non-rhizosphere soils during the growth of Agrostis stolonifera. Soil Biol. Biochem. 32(6), 869-878 (2000).

81. Baudoin, E., Benizri, E. \& Guckert, A. Impact of artificial root exudates on the bacterial community structure in bulk soil and maize rhizosphere. Soil Biol. Biochem. 35(9), 1183-1192 (2003).

\section{Acknowledgements}

This work was funded by the National Natural Science Foundation of China (41201291), the Agricultural Science and Technology Innovation Program of China (ASTIP-TRIC06) and the Science and Technology Project of Hubei Tobacco Company (027Y2019-017).

\section{Author contributions}

J.G.Z. designed the research. J.Y.Z. and J.X.Z. carried out the experiments and wrote the manuscript. L.G., R.W. and J.G. helped to execute the experiments and performed the analysis. W.L., G.S. and F.K. commented on the manuscript. All authors reviewed the manuscript.

\section{Competing interests}

The authors declare no competing interests.

\section{Additional information}

Correspondence and requests for materials should be addressed to J.Z. 
Reprints and permissions information is available at www.nature.com/reprints.

Publisher's note Springer Nature remains neutral with regard to jurisdictional claims in published maps and institutional affiliations.

(c) (i) Open Access This article is licensed under a Creative Commons Attribution 4.0 International License, which permits use, sharing, adaptation, distribution and reproduction in any medium or format, as long as you give appropriate credit to the original author(s) and the source, provide a link to the Creative Commons licence, and indicate if changes were made. The images or other third party material in this article are included in the article's Creative Commons licence, unless indicated otherwise in a credit line to the material. If material is not included in the article's Creative Commons licence and your intended use is not permitted by statutory regulation or exceeds the permitted use, you will need to obtain permission directly from the copyright holder. To view a copy of this licence, visit http://creativecommons.org/licenses/by/4.0/.

(C) The Author(s) 2021 